\title{
INVESTIGATION ELECTROPHYSICAL PROPERTIES OF ALLOTROPIC MODIFICATIONS OF CARBON IN THE RANGE OF TEMPERATURES 140-400 K
}

\author{
Goshev A.A., Eseev M.K. \\ Northern Arctic Federal University, Arkhangelsk, Russia \\ *E-mail: agoshev@ @otmail.com
}

\begin{abstract}
Annotation. The paper presents the results of the investigation allotropic modifications of carbon (coal, graphite, fullerenes, CNTs Dependences of conductivity on the field frequency in the temperature range $140-400 \circ \mathrm{K}$ are presented. The characteristic features associated with the structure and types of hybridization are revealed. Calculation of the activation energy of carriers was performed.
\end{abstract}

Currently, active attention is paid to research in the field of composite materials [1-3]. As an additive, for make composites of certain electrophysical and strength properties is widely used metal nanoparticles [3] and carbon in various allotropic forms. Owing to the large surface area, the high aspect ratio, the periodicity of the structure, and also the semimetallic conductivity, provided by p-electrons, carbon nanotubes (CNTs) are one of the most promising among carbon additives, which allows to minimize of the conductive additive in the composite. Significant increase in the conductivity ( $10^{5}$ orders) is achieve at concentrations of $0.1-0.2 \%$ by weight [2]. In connection with this, the question of the intrinsic properties of pure CNTs, the mechanisms of conduction, the distinctive features of the carbon from others allotropic state of carbon.

In this paper, the temperature studies of the electrophysical properties of carbon are presented. The measurement was carried out on a broadband dielectric spectrometer "Novocontrol concept 80" (frequency range $10^{-2}-10^{6} \mathrm{~Hz}$, temperature range $140-400 \mathrm{~K}$ ), measured values were conductivity $\sigma$ and dielectric losses $\varepsilon_{2}$. Studies of this kind have made it possible to reveal the characteristic features of various forms of carbon, associated with the crystal structure, to reveal various conduction mechanisms, depending on the temperature range Calculation of the activation energy of carriers for certain regions can be carried out within the framework of the follow relation:

$$
\sigma=\sigma_{0} \cdot \exp \left[\frac{-U}{k T}\right]
$$

It is established that the frequency dispersion (at a fixed temperature) is clearly pronounced in fullerenes, the increase in conductivity with frequency is due to the polarization conductivity, which is typical for dielectrics (see Fig. 1 The same effects are observed in coal and graphite, but have a more local character (coal $-10^{5} \mathrm{~Hz}$, graphite $-10^{6} \mathrm{~Hz}$,), which is an indicator of greater "metality". In the all frequency range conductivity of CNTs is monochromatic. "Wave" effects in the coordinates Ln [ $\sigma]$ from T 
are related to the transition of electrons to the molecular orbital (Fig.1 a), b)). The regions deviating from the dependence (1) allow us to introduce the dependence of the activation energy as a function from temperature.
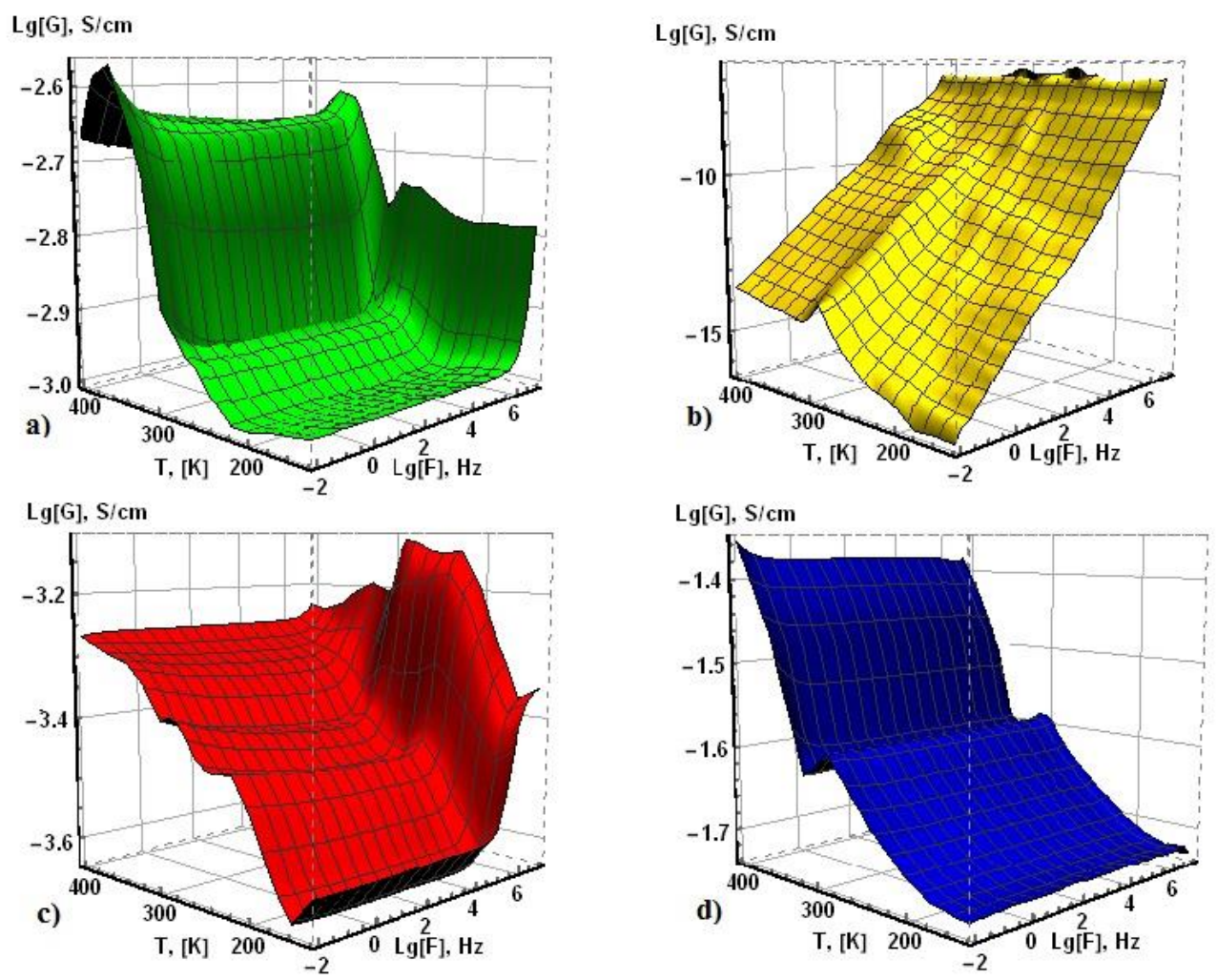

Fig. 1. Dependence of the conductivity on the frequency of the external field on the temperature a) graphite, b) fullerenes, c) coal, d) Taunit-MD CNT.

1. Eletskii A., Knizhnik A. et al., Phys. Usp., 58, 209 (2015).

2. Goshev A., Eseev M. et al., J. Phys. Conf. Series.,741, 012191 (2016).

3. Kudryashov M., Mashin A. et al., Tech. Phys., 59, 1012. (2014)

\title{
INVESTIGATION OF ACTIVATIVE CONDUCTIVITY IN CNT AND F-CNT IN THE RANGE OF TEMPERATURES 140-470 $\circ \mathrm{K}$
}

\author{
Goshev A.A., Eseev M.K., Volkov A.S. \\ Northern Arctic Federal University, Arkhangelsk, Russia \\ *E-mail: agoshev@ @otmail.com
}

Annotation. In the work by the method of dielectric relaxation spectroscopy, activation of p-electronic orbitals in CNT and F-CNT was investigated. The activation energy of carriers in different range was estimated. Dependences of conductivity and dielectric losses on the frequency of the alternating field in the temperature range 140-470 K are presented. 